\title{
CITRA IBU KOTA PALEMBANG DALAM HISTORIOGRAFI BARAT PADA ABAD XIX
}

\author{
THE IMAGE OF PALEMBANG CAPITAL CITY \\ IN WESTERN HISTORIOGRAPHY IN THE XIX CENTURY
}

Joshua Jolly Sucanta Cakranegara

Departemen Sejarah, Fakultas Ilmu Budaya, Universitas Gadjah Mada

Bulaksumur, Yogyakarta

Email: joshua.jolly.s.c@mail.ugm.ac.id

DOI: 10.36424/jpsb.v7i1.217

Naskah Diterima: 02 September 2020 Naskah Direvisi: 09 Mei 2021

Naskah Disetujui: 09 Mei 2021

\begin{abstract}
Abstrak
Artikel ini bertujuan membahas citra ibu kota Palembang dalam historiografi Barat pada abad ke-19. Hal ini dilatarbelakangi oleh berbagai faktor, seperti kejayaan Sriwijaya di masa lampau serta kehidupan masyarakatnya di tepi Sungai Musi yang menjadi daya tarik orang Barat sejak meningkatnya hegemoni Barat di Nusantara pada abad ke-17 dan abad ke-18. Artikel ini menggunakan metode penelitian sejarah dengan menganalisis berbagai historiografi oleh para penulis dan pengelana Barat sebagai sumber primer. Hasil penelitian menunjukkan bahwa setelah penaklukan Kesultanan Palembang, ibu kota Palembang mengalami proses konstruksi citra simbolik yang tidak terlepas dari romantisme Barat. Semboyan "Venesia dari Timur" pun menjadi representasi atas kompleksitas kehidupan masyarakat dan bentang alam ibu kotaPalembang sekaligus identitas sosial-budaya ala Barat oleh Belanda yang melekat atas ibu kota Palembang pada abad ke-19, meski citra tersebut diruntuhkan oleh mereka sendiri pada akhirnya.
\end{abstract}

Kata Kunci: ibu kota Palembang, citra, historiografi Barat, konstruksi simbolik, identitas sosial-budaya.

\begin{abstract}
This article aims to discuss the image of Palembang capital city in Western historiography in the $19^{\text {th }}$ century. This is motivated by various factors, such as the glory of Sriwijaya in the past and the life of its people on the banks of the Musi River which has attracted Westerners since the increasing of Western hegemony in
\end{abstract}


Nusantara in the $17^{\text {th }}$ and $18^{\text {th }}$ centuries. This article uses a historical research approach by analyzing various historiographies by Western writers and travelers as primary sources. The results showed that after the conquest of the Palembang Sultanate, the Palembang capital city experienced a symbolic image construction process that was inseparable from Western romanticism. The slogan "Venice from the East" also represents the complexity of people's lives and the landscape of the capital city of Palembang as well as the Western-style socio-cultural identity by the Dutch which was attached to the capital city of Palembang in the $19^{\text {th }}$ century, even though this image was destroyed by them in the end.

Keywords: Palembang capital city, image, Western historiography, symbolic construction, socio-cultural identity

\section{PENDAHULUAN}

Palembang saat ini merupakan ibu kota Provinsi Sumatra Selatan. Sebagai ibu kota yang menjadi pusat dari pemerintahan dan kehidupan masyarakat di Sumatra Selatan, Palembang selalu memiliki daya tarik tersendiri sepanjang sejarahnya. Jika ditarik jauh ke belakang, Palembang identik dengan salah satu kemaharajaan yang gemilang di masa lampau, yaitu Sriwijaya. Setelah kegemilangan Sriwijaya berakhir dan digantikan oleh hegemoni Barat, Palembang yang berada di tepi Sungai Musi menjadi perhatian Barat, terutama sejak abad ke-17 hingga abad ke-18. Hal ini memuncak pada abad ke-19, ketika Belanda mulai membangun sebuah tanah jajahan bernama Hindia Belanda dan Palembang menjadi salah satu incaran Belanda dalam menanamkan hegemoninya. Setelah konflik berkecamuk, Palembang mengalami proses konstruksi citra simbolik yang tidak terlepas dari romantisme Barat.

Jika dikaitkan dengan memori kolektif bangsa Indonesia, Palembang sebagai ibu kota tidak terlepas dari kegemilangan Sriwijaya pada masa lampau. George Coedès, seorang arkeolog Prancis, mengemukakan hasil penelitiannya tentang arkeologi di Asia Tenggara pada 1918 bahwa pusat Kerajaan Sriwijaya terletak di Palembang. Hal ini kemudian dibantah oleh para peneliti Indonesia. Slamet Muljana, seorang filolog dan sejarawan, menunjukkan bahwa salah satu akar perdebatan pusat Kerajaan Sriwijaya adalah penyamarataan toponim "Shih-li-fo-shih" dengan "San-fotsi" yang diduga kuat merupakan nama Sriwijaya dalam pelafalan Tiongkok. 
Selain itu, Soekmono, seorang arkeolog, juga berkeberatan dengan pernyataan Coedès. Pada 1954, ia menyimpulkan bahwa Jambi merupakan lokalisasi atau pusat Kerajaan Sriwijaya yang jauh lebih akurat. Meski demikian, Muljana menekankan bahwa lokalisasi Sriwijaya di Palembang juga tidak sepenuhnya keliru. Hal ini dapat dilihat dari tulisan Sejarah Dinasti Ming yang menegaskan bahwa ibu kota Kerajaan Sriwijaya yang pernah dikunjungi oleh Pendeta I-tsing disebut Ku-Kang atau Palembang (Muljana, 1981: 30-66; 2011: 105-129).

Terlepas dari perdebatan tersebut, Palembang sejak periode klasik telah menjadi salah satu kota yang memiliki daya tarik tersendiri karena keberadaan sungai-sungai di sekitarnya. Keberadaan Sungai Musi yang bermuara ke Selat Bangka serta sungai yang lain menyebabkan Palembang dinilai sebagai kota yang strategis, baik bagi daerah pedalaman maupun pesisir, dalam hubungan perdagangan maritim (Hanafiah, 1995: 69). Senada dengan hal itu, Mestika Zed menyebut bahwa Palembang dikenal sebagai pusat kerajaan maritim terpenting di Asia Tenggara serta penghubung pusat-pusat perniagaan trans-Asia antara Laut Tiongkok dan (Samudra) Hindia (Zed, 2003: 33). Dengan demikian, banyak kerajaan berkembang di sana, mulai dari Sriwijaya, kemudian Kerajaan Melayu Dharmasraya, hingga Kerajaan Palembang yang bertransformasi menjadi Kesultanan Palembang sejak abad ke-16.

Memasuki abad ke-17, orang-orang Barat, terutama Belanda dan Inggris melakukan penjelajahan samudra ke Nusantara. Sejak abad ini, persaingan dagang antara VOC atau Vereenigde Oostindische Compagnie (Belanda) dan EIC atau East Indies Company (Inggris) semakin kentara, salah satunya terjadi di Palembang dalam hal perdagangan merica. Pada saat itu, Palembang masih menjadi negara bawahan (vassal) dari kekuasaan Jawa (Mataram Islam dan Banten) di sisi lain. Hal ini menyebabkan terjadinya persekutuan dan perseteruan yang dinamis sepanjang dua abad. Pada akhir abad ke-18, status vassal ini pun berakhir (Andaya, 2016: 79-129).

Sepanjang periode tersebut, Belanda tampil sebagai bangsa Barat yang sangat mendominasi. Palembang yang terkenal sebagai pos perdagangan terbaik di Nusantara berusaha dikuasainya melalui ambisinya untuk memaksa Palembang 
menandatangani "perjanjian anti-perdagangan" karena Belanda menganut sistem monopoli. Selanjutnya, praktik monopoli ini tampak sangat jelas dalam dua komoditas, yaitu lada dan timah di Palembang. Hal ini terbukti dari pendirian pos perdagangan VOC dan benteng di sana (Marsden, 1811: 358-359; Crawfurd, 1820b: 433-434, 1820c: 357-372, 450-470).

Latar belakang di atas menunjukkan bahwa perhatian bangsa Barat, terutama Belanda, sangat besar atas Palembang sejak abad ke-17 hingga memuncak pada abad ke-19 sebagai periode pembentukan tanah jajahan Hindia Belanda. Oleh sebab itu, rumusan masalah dalam penelitian ini adalah pembentukan citra atas ibu kota Palembang yang tercermin dalam historiografi Barat sepanjang abad ke-19. Rumusan masalah tersebut dijabarkan dalam tiga pertanyaan penelitian, yaitu sebagai berikut. Pertama, bagaimana proses penaklukan Kesultanan Palembang sebagai awal dari pembentukan citra atas ibu kota Palembang? Kedua, bagaimana citra ibu kota Palembang dalam hal kehidupan masyarakat sebagaimana tercermin dalam historiografi Barat? Ketiga, bagaimana citra ibu kota Palembang dalam hal bentang alam sebagaimana tercermin dalam historiografi Barat? Batasan spasial dalam penelitian ini adalah ibu kota Palembang (hoofdplaats van Palembang), meski konteks Kesultanan Palembang secara luas tidak dapat dipisahkan darinya. Batasan temporal dalam penelitian ini adalah sepanjang abad ke-19.

Konsep utama dalam penelitian ini adalah citra. Citra (image) dapat didefinisikan sebagai sebuah representasi mental yang parsial dan tersimplifikasi, yang dapat diperoleh melalui visualisasi untuk menyerupai sesuatu, baik individu, kelompok, peristiwa, tempat, maupun objek tertentu. Citra terbentuk secara skematis dan timbal balik. Itu berarti, orang membuat sebuah persepsi dan persepsi tersebut turut memengaruhi kehidupan orang tersebut. Dengan kata lain, citra menjadi penting sebagai salah satu cara manusia mempersepsikan lingkungan di sekitarnya secara ideal (Taal, 2003: 34).

Oleh karena itu, pembentukan citra atas sesuatu memiliki proses yang panjang dan tujuan yang kompleks. Dalam hal ini, pembentukan citra atas kota merupakan 
sebuah fenomena yang lazim. Berbagai hal dapat membentuk citra sebuah kota, mulai dari aspek fisik, seperti arsitektur dan lanskap, hingga aspek sosial-mental, seperti kehidupan bersama, memori, pengalaman, cerita, mitos, dan sebagainya. Dengan demikian, pembentukan citra dapat menjadi jalan untuk memahami "jiwa" atas sebuah kota dan merupakan sebuah titik tolak yang mumpuni dalam mengkaji kota lebih lanjut (Taal, 2003: 19-20).

Sejumlah penelitian terdahulu telah mendalami pembentukan citra atas ibu kota Palembang selama periode kolonial. Hal ini ditandai dengan penaklukan Kesultanan Palembang sebagaimana dikaji oleh M.O. Woelders (1975) dan Farida R. Wargadalem (2017). Setelah itu, orang Barat menaruh perhatian dalam kehidupan masyarakat ibu kota Palembang. Banyak peneliti telah menghasilkan kajian dengan fokus yang beragam. Jeroen Peeters (1997) menekankan dinamika perubahan religius di Palembang sejak 1841-1942. Di samping itu, Barbara Watson Andaya (2016) mengulas kehidupan masyarakat Sumatra Tenggara pada abad ke-17 hingga abad ke18 yang menjadi salah satu landasan kompleksitas kehidupan masyarakat ibu kota Palembang pada abad ke-19. Realitas pada abad ke-19 kemudian menjadi titik tolak yang penting bagi ibu kota Palembang ketika pada abad berikutnya ibu kota ini berhadapan dengan modernitas, sebagaimana dikaji oleh Ida Liana Tanjung (2019).

Pada akhirnya, hal ini pun tidak terlepas dari faktor bentang alam, salah satunya sungai sebagai faktor kunci dalam mengkaji sejarah Sumatra, sebagaimana dikemukakan oleh Gusti Asnan (2016). Makmun Abdullah dkk. (1984/1985) menyebut citra atas Palembang sebagai "kota dagang dan industri". Selain itu, Sandra Taal (2003) menyoroti pembangunan citra atas Palembang yang berada "di antara idealisme dan realitas". Pada akhirnya, pembangunan citra atau identitas ala Barat atas Palembang melalui julukan "Venesia dari Timur" oleh Peter J.M. Nas (2007) dan Dedi Irwanto Muhammad Santun (2011) yang disebut sebagai proses "produksi dan reproduksi simbolik" yang kemudian akan melekat pada periode selanjutnya. 


\section{METODE PENELITIAN}

Penelitian ini merupakan penelitian sejarah. Setelah menentukan topik dalam rumusan masalah, penulis mengumpulkan sejumlah sumber. Sumber primer dalam penelitian ini adalah historiografi berupa catatan dan kajian sezaman sepanjang abad ke-19 yang ditulis oleh orang Barat, baik Belanda, Inggris, hingga Amerika. Di samping itu, sumber sekunder yang digunakan adalah kajian dan literatur setelah abad ke-19 untuk mendukung argumentasi dalam sumber primer. Setelah mengumpulkan sumber, penulis melakukan kritik atau verifikasi sumber. Sumber-sumber yang dinilai valid kemudian diinterpretasi menggunakan metode analisis dan sintesis untuk menghasilkan fakta-fakta historis. Sejumlah fakta tersebut akhirnya disusun dalam sebuah kerangka narasi historis yang kronologis dan komprehensif.

\section{PEMBAHASAN}

\section{Proses Penaklukan Kesultanan Palembang}

Memasuki abad ke-19, Kesultanan Palembang dihadapkan dengan persaingan hegemoni antara dua bangsa Barat, yaitu Inggris dan Belanda. Akar persaingan ini telah terlihat sejak abad ke-17 ketika kedua bangsa Barat ini direpresentasikan dalam kongsi dagang, baik VOC oleh Belanda maupun EIC oleh Inggris. Persaingan ini semakin menghangat dalam kurun waktu 1811 hingga 1825. Menurut M.O. Woelders, Kesultanan Palembang tidak hanya menghadapi persaingan eksternal, tetapi juga persaingan internal antara "sultan tua" (de oude sultan) Mahmud Badaruddin dengan "sultan muda" (de jonge sultan) Ahmad Najamuddin. Ia menyebut bahwa sejak 1804 hingga 1823, terjadi enam kali pergantian kekuasaan di Kesultanan Palembang akibat persaingan dua dinasti tersebut.

Akibatnya, Kesultanan Palembang menjadi tidak stabil, terlebih ketika berhadapan dengan Inggris dan Belanda. Woelders merangkum dinamika sepanjang 14 tahun yang krusial tersebut sebagai berikut. September 1811-Mei 1812 merupakan periode kemerdekaan pertama. Mei 1812-Desember 1816 merupakan periode kekuasaan Inggris. Desember 1816-Juni 1819 merupakan periode kekuasaan Belanda. 
Juni 1819-Juni 1821 merupakan periode kemerdekaan kedua. Juli 1821-Oktober 1825 merupakan periode ekspansi Belanda untuk menaklukkan Kesultanan Palembang dan membangun tanah jajahan Hindia Belanda (Woelders, 1975: 1-2).

Rivalitas internal antara sultan tua dan sultan muda ini juga termanifestasi dalam bangunan fisik yang disebut sebagai "Kuta Lama" (de oude kraton) dan "Kuto Besak" (de nieuwe kraton). Djohan Hanafiah menyebut bahwa Kuta Lama dan Kuto Besak "bagaikan dua saudara yang berdiri tegak bergandengan tangan di tepian Sungai Musi”. Dua benteng ini menjadi simbol pergantian kekuasaan yang silih berganti di dalam Kesultanan Palembang, sekaligus saksi bisu perang Kesultanan Palembang dengan Inggris dan Belanda untuk mempertahankan kedaulatannya, meski pada akhirnya jatuh ke tangan Belanda. Kuto Besak didirikan pada akhir abad ke-18 oleh Sultan Muhammad Bahauddin (Hanafiah, 1989: 1-7).

Pada masa pendirian Kuto Besak ini dan setelahnya, Kesultanan Palembang mengalami kemajuan, khususnya dalam bidang ekonomi. Hal ini tidak terlepas dari pembubaran VOC pada 1799. Sultan Ratu Mahmud Badaruddin II yang merupakan putra dari Sultan Muhammad Bahauddin dinobatkan sebagai Sultan Palembang pada 1804. Ia memperkuat pemerintahan dengan mengangkat tiga adiknya sebagai penasihat sultan serta mengangkat sejumlah pejabat kerajaan atas empat bidang utama, yaitu bidang pemerintahan dan keamanan oleh Pangeran Notodirojo, bidang agama oleh Pangeran Penghulu Nato Agamo, bidang peradilan oleh Pangeran Kerto Negoro, dan bidang perdagangan oleh syahbandar. Ia juga menempatkan wakil pemerintah pusat hingga ke daerah pedalaman (uluan) untuk memperkuat pemerintahan di sana (Wargadalem, 2017: 19-26).

Salah satu hal yang disinggung oleh para penulis Barat dalam historiografinya tentang penaklukan Kesultanan Palembang adalah konflik eksternal antara Inggris dan Kesultanan Palembang. J.C. Baud, misalnya, menulis bahwa 1811 merupakan “awal dari serangkaian perang dan pemberontakan yang berakhir dengan runtuhnya keluarga kerajaan yang berkuasa, dan aneksasi kerajaan mereka di bawah Belanda dengan nama Karesidenan Palembang dan Banka" sekaligus "tahun pembunuhan 
yang keji atas orang-orang Belanda yang hendak dikembalikan ke Jawa”. Sejak 11 September 1811, Lord Minto mendeklarasikan Jawa dan daerah-daerah bawahannya berada di bawah kekuasaan EIC. Raffles yang menjadi Gubernur Jenderal sejak saat itu bertanggung jawab atas pembunuhan tersebut. Hal ini menjadi sebuah sejarah yang diterima (accepted history) bagi sejarawan kolonial Belanda (Baud, 1852: 7-20).

Meski demikian, hal tersebut dibantah oleh John Bastin. Dalam tulisannya, ia menyebut bahwa pembunuhan keji pada 14 September 1811 tidak terlepas dari peran Sultan Mahmud Badaruddin yang berkirim surat dengan Raffles. Menurut Bastin, surat-surat tersebut tidak begitu diperhatikan oleh Baud sehingga kesimpulan bahwa Raffles menjadi satu-satunya pihak yang bertanggung jawab tidaklah tepat (Bastin, 1953: 300-320). Selain itu, alasan yang jauh lebih kuat adalah pengingkaran janji kemerdekaan yang diberikan Raffles kepada Sultan Mahmud Badaruddin. Dengan demikian, ia menegaskan kembali bahwa Sultan Mahmud Badaruddin tidak dapat dilepaskan dari peristiwa tragis tersebut (Bastin, 1954: 64-80).

Setelah Kesultanan Palembang takluk, P.J. Veth menyebut bahwa wilayah ini menjadi Karesidenan Palembang yang dibagi ke dalam lima afdeeling pada 1855 , yaitu (1) Ibu Kota Palembang (Hoofdplaats Palembang), Iliran dan Banjoe Asin, Kemering Ilir, Ogan Ilir, Moesi Ilir, Lematang Ilir; (2) Tebing Tinggi, Ampat Lawang, Lematang Oeloe, Moesi Oeloe, Kikim, Redjang, Pesoemah; (3) Ogan Oeloe, Kemering Oeloe, Enim, Semindo, Kisam, Makakau; (4) Rawas; dan (5) Djambi (Veth, 1867: 105-106). Dengan demikian, Palembang didaulat sebagai ibu kota karesidenan. Setelah proses penaklukan tersebut, citra atas ibu kota Palembang mulai terbangun atau terbentuk, sebagaimana tercermin dalam berbagai historiografi Barat yang ada. Pembentukan citra tersebut tidak terlepas dari dinamika dan pengaruh pemerintah kolonial Hindia Belanda yang sedang berkuasa pada waktu itu.

\section{Citra Ibu Kota Palembang dalam Hal Kehidupan Masyarakat}

Penaklukan Kesultanan Palembang oleh Belanda berakibat pada pesatnya perubahan kehidupan masyarakat perkotaan. Pemerintah kolonial Hindia Belanda 
berhadapan dengan penduduk beserta elite lokal yang tidak sedikit. Struktur sosial pun berkembang semakin kompleks (Taal, 2003: 58). Oleh sebab itu, pemerintah kolonial pun mulai mengatur sejumlah hal, salah satunya pembentukan kampung. Kampung-kampung ini memiliki keunikan tersendiri yang membedakan Palembang dengan kota-kota lain, yaitu penamaannya dengan angka dan disertai nama distrik letak kampung itu berada, seperti "1 ilir" dan "1 ulu" (de Clercq, 1877: 174).

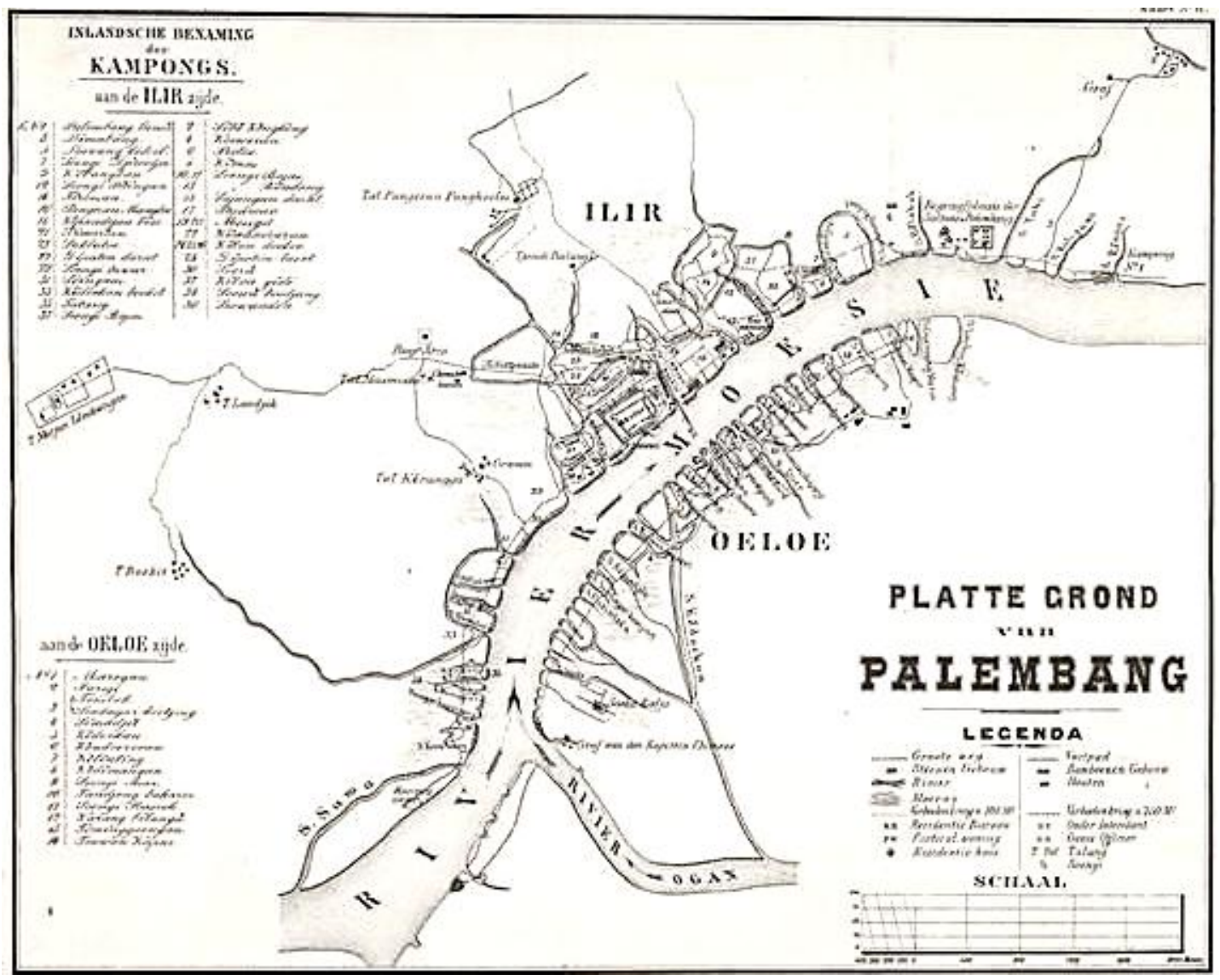

Gambar 1. Peta Ibu Kota Palembang beserta Nama Kampung pada Abad ke-19. Sumber: F.S.A. de Clercq, 1877: 175.

Menurut J.I. van Sevenhoven, seorang komisaris Belanda di Palembang sejak 1821, penduduk ibu kota Palembang dapat dibagi menjadi dua golongan, yaitu golongan priayi (turunan raja-raja atau kaum ningrat) dan rakyat. Golongan priayi 
terdiri atas pangeran, raden, dan mas agus. Di samping itu, golongan rakyat terdiri atas kiai-mas, kiai-agus, dan rakyat jelata. Rakyat jelata terdiri atas orang miji, orang senan (snouw), orang yang menggadaikan diri, dan budak. Beragam etnis juga tinggal disana, seperti etnis Tionghoa, Arab, dan lain-lain (van Sevenhoven, 1823: 63-76).

W.L. de Sturler menyebut orang Tionghoa di sana yang berjumlah sekitar 1.500 jiwa pada 1840-an, sebagai "pedagang, seperti di mana-mana di Kepulauan Hindia" yang "berperilaku sebagai penduduk yang pendiam dan rajin, yang tidak peduli dengan kesewenang-wenangan para pangeran" sehingga mereka "telah menikmati sejumlah kemakmuran”. Mereka tinggal di rumah rakit, merayakan pesta, juga melakukan kebaktian di kuil mereka. Selain itu, orang Arab yang berjumlah lebih sedikit, sekitar 500 jiwa, menikmati lebih banyak kebebasan dari para pangeran Melayu, namun berperilaku tidak arif di sana (de Sturler, 1843: 194-196).

C.F.E. Praetorius mencatat bahwa penduduk ibu kota Palembang berjumlah sekitar 30.085 jiwa, di antaranya 27.690 bumiputra, 921 Arab, dan 1.474 Tionghoa. Jumlah ini diduga berasal dari sekitar 1830-an (Praetorius, 1843: 75). Dari catatan ini, dapat disimpulkan bahwa heterogenitas penduduk di ibu kota Palembang adalah sebuah keniscayaan. Dalam perkembangan selanjutnya, hal ini kemudian menyebabkan terjadinya stratifikasi sosial yang kentara.

Secara umum, stratifikasi sosial penduduk di Karesidenan Palembang dibagi menjadi dua, yaitu penduduk iliran dan uluan. Dalam berbagai literatur, ibu kota Palembang selalu diposisikan sebagai titik tolak atas dua stratifikasi sosial ini. Penduduk di ibu kota Palembang tergolong sebagai penduduk iliran yang "dilahirkan dengan bakat dagang" (van Alkemade, 1883: 66). Mereka juga seringkali mengasosiasikan dirinya dengan "bagian dari peradaban dunia maju". Di sisi lain, penduduk uluan dicap sebagai orang "udik" yang penuh dengan keterbelakangan. Meski demikian, bukan berarti tidak ada hubungan kerja sama antara penduduk iliran dan uluan. Perdagangan (ekonomi) merupakan salah satu bentuk hubungan kerja sama yang terus terjalin (Peeters, 1997: 37-42; Zed, 2003: 34-37; Santun, Murni, dan Supriyanto, 2010: 1-2, 164-167; Tanjung, 2019: 34-38). 
Oleh karena perdagangan menjadi vital, Pelabuhan Palembang berkembang semakin pesat dengan pendirian sejumlah benteng dan kantor agen perdagangan di sana pada 1824. Pelabuhan ini merupakan pusat perdagangan komoditas perkebunan dari daerah pedalaman, juga timah dari Bangka. Oleh sebab itu, tidak mengherankan bila banyak kapal asing bersandar di sana dan Pelabuhan Palembang dijadikan sebagai pelabuhan ekspor-impor oleh pemerintah kolonial Hindia Belanda untuk menandingi kejayaan Inggris melalui Pelabuhan Tumasik (Supriyanto, 2013: 73-80).

Keunggulan ini pun diakui oleh Mayor M.H. Court bahwa, "Dari seluruh pelabuhan di wilayah orang-orang Melayu, Palembang telah terbukti menjadi pelabuhan yang paling aman ... seperti dinyatakan oleh orang bumiputra dan orang Eropa" (Court, 1821: 109). Dengan demikian, menjadi jelas alasan mengapa penduduk ibu kota Palembang menjadi heterogen dengan berbagai etnis, yaitu hadirnya para pedagang asing yang kemudian menetap di sana (Abdullah dkk., 1984/1985: 26-27).

Keunggulan Pelabuhan Palembang juga terlihat dalam jumlah ekspor-impor (uitvoer-invoer) yang meningkat setiap tahunnya. Prateorius mencatat kenaikan jumlah ekspor sejak 1821 hingga 1832, yaitu dari 43.808,21 gulden menjadi 301.102,75 gulden; juga kenaikan jumlah impor, yaitu dari 4.925 gulden menjadi 433.998,91 gulden (Praetorius, 1843: 73). Selanjutnya, Veth juga memaparkan peningkatan sejak 1846 hingga 1863 pada jumlah ekspor, yaitu dari 691.270 gulden menjadi 1.131.104 gulden, juga pada jumlah impor, yaitu dari 1.041 .312 gulden menjadi 1.462.914 gulden (Veth, 1867: 78).

Di samping perdagangan, mata pencaharian penduduk di ibu kota juga beragam. Praetorius menjabarkan secara terperinci bahwa terdapat pembagian pekerjaan antara penduduk laki-laki dan perempuan. Penduduk laki-laki umumnya menjadi pengrajin tertentu, seperti pengrajin emas, perak, kuningan, timah, kaleng, dan besi. Selain itu, mereka juga bekerja sebagai tukang ukir, pengrajin sarung keris, tukang mebel, pengrajin tepak, pelarik gading, tukang kayu, penggergaji kayu, pembuat perahu, pelukis, pengrajin tikar, pembuat batu bata, pembakar kapur, tukang 
batu, pengumpul daun nipah, pembuat kajang dan atap, pembuat sepatu, pengrajin tikar rotan, penjilid buku atau kitab, penulis/penyalin kitab, kepala sekolah pengajian, tukang cuci, pemain gamblang, petani ladang, petani kebun, peternak kerbau, peternak bebek, peternak ayam, kuli, pelaut, penambak tanah, hingga pemotong kayu bakar. Di sisi lain, penduduk perempuan umumnya menjadi penenun, seperti penenun songket, katun, dan kain sutra. Selain itu, mereka juga bekerja sebagai pemintal benang, pengrajin topi/kopiah, penjahit, penyulam, pengrajin batik, pembuat minyak kemiri, pembuat sisir rambut, hingga dukun bayi (Praetorius, 1843: 10-25).

Selain beragam mata pencaharian tersebut, satu mata pencaharian penting yang tidak luput adalah nelayan. Praetorius menerangkan bahwa penduduk ibu kota Palembang akan turun ke sungai, danau, dan muara untuk menangkap ikan pada musim yang baik (Praetorius, 1843: 25). Hal ini juga ditegaskan oleh de Sturler bahwa sebagian besar penduduk ibu kota Palembang mencari ikan di daerah pedalaman, sebab mereka takut dengan banyak bajak laut di daerah pesisir (de Sturler, 1843: 154-155).

Di samping itu semua, sebuah kisah menarik datang dari seorang petualang Amerika bernama Walter Murray Gibson. Kedatangan petualang secara umum pada abad ke-19 merupakan hal yang lazim, sebab periode tersebut merupakan "abad penjelajahan swasta, domestik, maupun internasional”. Menariknya, para petualang Amerika lebih dari sekadar "pelancong romantis" sebab mereka pun tidak terlepas dari konstelasi politik lokal, termasuk Gibson. Ia telah menginjakkan kaki di Sumatra pada 17 Januari 1852. Sebelumnya, para petualang menghadapi persoalan pelik dengan pemerintah kolonial Hindia Belanda. Inilah yang disebut sebagai "titik kritis dalam sejarah Palembang". Oleh sebab itu, Gibson disambut dingin oleh administrator lokal, namun disambut hangat oleh masyarakat dan penguasa lokal di sana. Belum lama berada di sana, ia ditangkap dengan tuduhan pengkhianatan dan dihukum 12 tahun penjara. Meski demikian, ia memilih kabur dari tahanan pada April 1853. Setelah itu, ia menaruh simpati terhadap masyarakat Palembang dan antipati terhadap pemerintah kolonial Hindia Belanda (Locher-Scholten, 2008: 117-120). 
Pada 1855 alias tiga tahun setelah pelariannya, Gibson mengalami apa yang kemudian disebut sebagai sebuah "kisah romantisme dan kepolosan luar biasa", yaitu diskusinya dengan keluarga Pangeran Melayu (kepala suku) dan pengalamannya di pesta pernikahan orang Tionghoa. Dalam kisah pertama, Gibson menyatakan simpatinya terhadap orang Sumatra dan antipatinya terhadap "penjarah besar bernama Jan Company" melalui percakapannya dengan mereka. Mereka menyebut orang Wolanda (Belanda) sebagai “orang yang penuh kebencian dan buruk rupa; mereka memperlakukan orang Islam seperti anjing, dan muka mereka sejelek orang Kubu (Orang Rimba)". Pangeran Melayu menyebut Orang Rimba sebagai "sampah masyarakat", "makhluk yang dikutuk Allah", hingga "makhluk yang lebih rendah daripada manusia" (Gibson, 1855: 179-181).

Dalam kisah kedua, Gibson menceritakan pengalamannya ketika menghadiri pesta pernikahan orang Tionghoa di sebuah rakit di atas sungai (rumah terapung) dengan tuan rumah bernama Oey Tsee Yang. Menariknya, pesta tersebut tidak hanya dihadiri oleh orang Tionghoa, tetapi juga para bangsawan Melayu. Gibson menikmati jamuan makan dalam pesta tersebut dan terkejut ketika mengetahui mereka memakan anjing dan sarang burung walet. Kisah ini pun ia tutup dengan cerita tentang Perdana Menteri Krama Djaya yang bersama Sultan Badaruddin "dengan gagah melawan Belanda". Sang perdana menteri dikisahkan sebagai orang yang sangat baik hati dan orang-orang Palembang sangat menyayanginya. Ketika Kompeni (Belanda) menangkap dan mengasingkannya, segenap anak, saudara, hingga ratusan ribu orang berdoa kepada Allah agar ia kembali (Gibson, 1855: 206-211).

\section{Citra Ibu Kota Palembang dalam Hal Bentang Alam}

Menurut Barbara Watson Andaya, bentang alam dapat menjadi sebuah “ensiklopedia sosial" (Andaya, 2016: 25). Hal ini berarti bentang alam berpengaruh terhadap realitas sosial kehidupan masyarakat yang mendiaminya, seperti nama ibu kota "Palembang". Menurut catatan van Sevenhoven, asal usul kata "Palembang" tidak terlepas dari pembersihan dengan air. Misal, limbang berarti membersihkan biji 
atau logam dari tanah atau benda luar dan lemba berarti tanah yang dihanyutkan air ke tepi (van Sevenhoven, 1823: 42-43).

Di samping itu, keadaan bentang alam Palembang dan sekitarnya tidak terlepas dari fenomena air surut dan pasang serta musim hujan lebat disertai angin kencang dan petir. Keseimbangan ekologis demikian menyebabkan "Palembang dapat dianggap sehat". Dengan kondisi geografis yang strategis tersebut, Kesultanan Palembang memilih mengembangkan ibu kota di sana "secara bijaksana dan penuh perhitungan”. Sungai Ogan dan Komering dari hulu yang menyatu dengan Sungai Musi di hilir merupakan "satelit" atau penghubung antara daerah pedalaman dan pesisir yang dapat dilalui oleh kapal besar hingga ke pedalaman. Oleh sebab itu, konektivitas ini pun semakin menguntungkan Kesultanan Palembang untuk mengontrol apa yang terjadi, baik di pedalaman maupun pesisir, dari pusat pemerintahan atau ibu kota (van Sevenhoven, 1823: 41-45).

Palembang identik dengan Sungai Musi yang merupakan muara dari sembilan sungai besar atau "Batang Hari Sembilan" yang mengalir di Sumatra Selatan, yaitu Klingi, Bliti, Lakitan, Rawas, Rupit, Lematang, Leko, Ogan, dan Komering (de la Faille, 1929: 320). Sungai-sungai tersebut terbilang lebar sehingga A.H.W. de Kock menulis bahwa jembatan tidak dapat dibangun di sana untuk menghubungkan kedua tepi sungai tersebut (de Kock, 1846: 281). Dengan banyaknya sungai tersebut, bentuk dan keadaan tanah ibu kota Palembang seolah-olah terlihat berpulau-pulau sehingga orang Belanda menjuluki ibu kota Palembang sebagai de Stad der Twintig Eilanden (Kota Dua Puluh Pulau) (Bruining, 1822: 14; Gramberg, 1878: 96).

Di antara "pulau-pulau” tersebut, Kota Lama dan Kuto Besak berdiri sebagai pusat pemerintahan. Setelah Kota Lama dihancurkan, Kuto Besak dialihfungsikan menjadi pusat pemerintahan ibu kota Karesidenan Palembang. Kuto Besak terletak seolah-olah berada di atas pulau yang dikelilingi oleh Sungai Musi sehingga kawasan ini disebut sebagai "Tanah Kraton”. Citra benteng tersebut sangat kuat sehingga J.A. van Rijn van Alkemade menulis bahwa "benteng ini adalah salah satu benteng yang 
terbesar di Kepulauan Hindia dan tidak dapat dikalahkan oleh musuh di pedalaman" (van Alkemade, 1883: 51-69).

Dengan keberadaan pulau-pulau tersebut, praktis penggunaan rakit menjadi dominan di sana. Oleh karena itu, orientasi kehidupan masyarakat ibu kota Palembang adalah riverine culture, yaitu kebudayaan penduduk yang berkehidupan di tepian sungai, atau dalam bahasa ringkas disebut "budaya dayung" (Hanafiah, 1995: 70). Realitas demikian ditegaskan dalam sejumlah catatan Tiongkok yang menggambarkan kehidupan penduduk ibu kota Palembang, bahwa mereka tinggal di atas perahu atau membuat rumah dengan bambu di atas air, yang disebut sebagai "rumah rakit", sebagaimana dijelaskan sebelumnya (Hanafiah, 1995: 22).

Bentang alam ibu kota Palembang juga dilukiskan oleh John Crawfurd, Residen Yogyakarta sewaktu Inggris berkuasa atas Jawa pada 1811 hingga 1816. Ia menyebut bahwa kehidupan masyarakat Palembang mencerminkan "bentuk-bentuk yang paling luar biasa" atas kehidupan suku maritim. Hal ini tidak terlepas dari bentang alamnya yang didominasi oleh aliran sungai dan daerah rawa di hilir. Sebagian besar tempat tinggal dibangun di atas rakit-rakit bambu yang dapat dipindahkan dan ditambatkan pada tiang pancang di tepi sungai. Oleh sebab itu, Crawfurd menegaskan bahwa air atau sungai menjadi sarana transportasi sekaligus komunikasi yang utama, dan bahkan nyaris satu-satunya di ibu kota Palembang (Crawfurd, 1820a: 171-172).

Hal senada juga diungkapkan oleh Alfred Russel Wallace, seorang penjelajah Inggris terkemuka di Nusantara (1823-1913). Pada 1861, ia mendarat di Palembang. Wallace menyebut bahwa daerah hilir didominasi oleh rawa-rawa sehingga membutuhkan waktu berjam-jam baginya untuk menyandarkan kapal ke darat. Ia melukiskan ibu kota Palembang sebagai kota yang besar dengan sungai-sungai yang sama dengan Sungai Thames dan Greenwich di Inggris. Meski demikian, lebar sungai ini menjadi sempit akibat rumah-rumah yang dibangun di atas tiang atau di atas rakitrakit bambu, sebagaimana penjelasan Crawfurd sebelumnya. Selain itu, ibu kota Palembang dan daerah sekitarnya juga terletak di sebuah dataran tinggi sempit yang 
ditumbuhi dengan banyak pohon besar sebagai tempat tinggal "koloni tupai yang sudah agak jinak" (Wallace, 1869: 190-192).

Pembangunan rumah dari kayu atau bambu tersebut bukanlah tanpa alasan. Selain karena faktor alam, hal ini juga tidak terlepas dari perintah raja yang melarang pembangunan rumah berbahan batu karena hanya bangunan keraton atau kerajaan yang berbahan batu. De Sturler mendeskripsikan rumah-rumah penduduk kaya berbahan kayu tersebut sangat apik, "berpanel rapi, didekorasi dengan dedaunan dan ukiran yang indah, ... dan di atas kapnya dilapisi dengan berbagai jenis genteng". Rumah demikian disebut dikerjakan oleh pekerja terampil dengan sangat rapi. Di samping itu, rumah-rumah penduduk kebanyakan menggunakan bahan dasar bambu yang dilengkapi tiang kayu dan ditutupi daun lontar (de Sturler, 1843: 184-185).

Kebudayaan sungai ini juga diadopsi oleh orang-orang Eropa yang tinggal di ibu kota Palembang. Van Sevenhoven dan van Alkemade menyebut bahwa orang Eropa (Barat) lebih menyukai tinggal di rakit daripada rumah biasa di daratan. Rakit dinilai memiliki banyak kelebihan, misal terletak di tengah-tengah aliran sungai yang membuat udara menjadi sejuk. Kesukaan ini terungkap dalam kesaksian berikut. "Duduk-duduk di serambi rakit orang Eropa sangat menyenangkan, mulai saat fajar tampak, sampai saat petang di pelupuk mata, karena angin yang berhembus sejuk. Pemandangan dari segala penjuru sungai sangat indah dinikmati, memberikan gambaran mengenai kehidupan sehari-hari di sungai yang indah dan luas ini" (van Sevenhoven, 1823: 47-48; van Alkemade, 1883: 67).

Gambaran atas bentang alam Palembang yang identik dengan sungai ditegaskan oleh Gusti Asnan bahwa hal tersebut menjadi vital bagi Palembang secara khusus maupun Sumatera secara umum. Alasannya, sungai merupakan rupa bumi yang sangat dominan di Sumatera. Sungai telah menjadi salah satu faktor dalam perjalanan sejarah masyarakat yang mendiami pulau tersebut, termasuk di Palembang (Asnan, 2016: 13). Bahkan, Veth telah menegaskan bahwa "jumlah sungai di Sumatra sangat banyak" meski ia tidak menyebut jumlah tersebut secara spesifik (Veth, 1867: $1)$. 
Selain bentang alam yang menarik dengan persilangan sejumlah sungai, ditambah cuaca yang mendukung, daerah ibu kota Palembang memiliki tingkat kesuburan tanah yang tinggi sehingga banyak tanaman dapat dibudidayakan oleh penduduk, seperti lada, kopi, cengkeh, hingga tembakau (Gramberg, 1878: 2). Bahkan, kekayaan tanaman ini dijuluki oleh de Sturler sebagai "kerajaan tanaman (plantenrijk), yang pertumbuhannya subur melampaui apa pun yang ditunjukkan di tempat lain di daerah tropis" dan "memiliki hampir semua tanaman yang tumbuh di pulau-pulau lain di Nusantara".

Di samping tanaman yang sudah disebutkan sebelumnya, berbagai tanaman komoditas pertanian, perdagangan, industri, dan obat-obatan juga dibudidayakan, antara lain beras, kapas, kayu hutan, kacang-kacangan, buah-buahan, ketumbar, bawang bombai, gambir (Terra japonica), rami (Urtica nivea), nila, kemenyan, hingga tanaman penghasil minyak, seperti kayu putih (Melaleuca leucadendron) dan jarak (palma Christi) (de Sturler, 1855: 36-37, 40-41).

Keindahan dan keunggulan Palembang telah menarik minat orang Barat atasnya. Ketika Palembang telah dikuasai oleh Belanda sejak dekade kedua abad ke19, banyak tulisan lahir untuk menggambarkan Palembang, terutama oleh para pejabat pemerintahan kolonial (Taal, 2003: 39). Para penulis kolonial selalu membuat sinonim keindahan kota dengan Kota Venesia, bahkan mengidentikkan ibu kota Palembang sebagai "Venesia dari Timur", de Venetie van het Oosten. Hal ini merupakan sebuah proses konstruksi simbolik sekaligus pembangunan citra ala Barat atas Palembang yang didominasi oleh "ruang air". Dominasi ini masih bertahan pada abad ke-19 dan mulai berubah orientasi ke ruang daratan pada abad ke-20 akibat intervensi pemerintah kolonial Hindia Belanda, terutama dalam hal penemuan dan pengeboran minyak bumi pada akhir abad ke-19 sehingga industrialisasi di Palembang terjadi secara masif (Abdullah dkk., 1984/1985: 43; Taal, 2003: 66). Dengan kata lain, identitas sosial-budaya "Venesia dari Timur" yang dibangun oleh orang Belanda pada awalnya justru "diruntuhkan" sendiri oleh mereka pada akhirnya (Nas, 2007: 638; Santun, 2011: 24-41). 


\section{PENUTUP}

Palembang tidak terlepas dari warisan kegemilangan Sriwijaya maupun Kesultanan Palembang pada masa lampau. Memasuki abad ke-19, Palembang dihadapkan dengan dua konflik, yaitu konflik internal dan konflik eksternal. Dua bangsa Barat, yaitu Belanda dan Inggris saling berebut pengaruh atas Palembang. Setelah penguasaan Belanda atas Kesultanan Palembang terjadi pada dekade kedua abad ke-19, para pejabat kolonial dan banyak orang Barat berdatangan ke Palembang yang didaulat kembali sebagai ibu kota Karesidenan Palembang. Penguasaan atau penaklukan ini menjadi jalan atas pembangunan atau pembentukan citra atas ibu kota Palembang yang tidak dapat terlepas dari dinamika dan pengaruh pemerintah kolonial Belanda yang sedang berkuasa pada waktu itu.

Kehidupan masyarakat ibu kota Palembang pada abad ke-19 memikat perhatian orang Barat. Mereka melihat sebuah kehidupan yang unik, yaitu kehidupan bercorak maritim. Oleh sebab itu, tidak mengherankan jika aktivitas perdagangan maritim yang disokong oleh Pelabuhan Palembang semakin menggeliat. Di samping itu, kompleksitas kehidupan masyarakatnya terlihat dari keberagaman atau heterogenitas yang ada, baik di kalangan penduduk bumiputra maupun orang asing. Hal ini tampak dalam stratifikasi yang berpengaruh dalam bidang politik, ekonomi, dan sosial, seperti penduduk iliran dan uluan; juga mata pencaharian yang beragam. Selain itu, anggapan bahwa orang Barat mendukung penaklukan Palembang oleh Belanda tidak sepenuhnya tepat. Seorang Amerika, misalnya, justru menaruh simpati yang besar kepada penduduk bumiputra serta antipatinya kepada pemerintah kolonial. Kisah demikian merupakan salah satu bentuk romantisme Barat yang turut membentuk citra atas kehidupan masyarakat ibu kota Palembang. Dengan kata lain, masyarakat ibu kota Palembang pada saat itu dicitrakan sangat kosmopolitan.

Di antara semua hal yang memikat orang Barat atas ibu kota Palembang, bentang alam menduduki tempat teratas. Sejumlah tulisan menunjukkan kekaguman orang Barat atas keindahan ibu kota Palembang yang didominasi oleh ruang air dengan Sungai Musi dan banyak sungai yang membelahnya serta rakit-rakit yang 
menjadi tempat tinggal sebagian besar penduduknya. Hal ini menjadi latar belakang terciptanya kebudayaan sungai yang menjadi orientasi kehidupan masyarakat di sana, yang juga juga diadaptasi oleh orang Barat. Dengan demikian, kekaguman atau romantisme ini bermuara pada pembangunan atau pembentukan citra simbolik atas ibu kota Palembang melalui julukan "Venesia dari Timur" sebagai representasi atas kehidupan masyarakat dan bentang alamnya, meski pada akhirnya julukan tersebut runtuh akibat industrialisasi yang masif oleh pemerintah kolonial Hindia Belanda. 


\section{DAFTAR PUSTAKA}

Abdullah, Makmun dkk. 1984/1985. Kota Palembang sebagai "Kota Dagang dan Industri”. Jakarta: Proyek Inventarisasi dan Dokumentasi Sejarah Nasional Direktorat Sejarah dan Nilai Tradisional Departemen Pendidikan dan Kebudayaan.

Andaya, Barbara Watson. 2016. Hidup Bersaudara: Sumatra Tenggara pada Abad XVII dan XVIII. Yogyakarta: Ombak.

Asnan, Gusti. 2016. Sungai dan Sejarah Sumatra. Yogyakarta: Ombak.

Bastin, John. 1953. "Palembang in 1811 and 1812 (Part I)" dalam Bijdragen tot de Taal-, Land-en Volkenkunde, Vol. 109, No. 4, hlm. 300-320.

Bastin, John. 1954. "Palembang in 1811 and 1812 (Part II)" dalam Bijdragen tot de Taal-, Land- en Volkenkunde, Vol. 110, No. 1, hlm. 64-88.

Baud, J.C. 1853. "Palembang in 1811 en 1812" dalam Bijdragen tot de Taal-, Landen Volkenkunde van Nederlandsch-Indië, Vol. 1, No. 1, hlm. 7-40.

Bruining, Gerbrand. 1822. De Heldhaftige Bevrediging van Palembang, Het Aldaar sints 1810 Vooraf Gebeurde, Wederlegging van Raffles en Court, en Voorloopige Korte Beschrijving van Palembang, Banca, enz. Met Twee Kaarten van de Palembangsche Groote Rivier. Rotterdam: Arbon en Krap.

Court, M.H. 1821. An Exposition of the Relations of the British Government with the Sultaun and State of Palembang and the Designs of the Netherlands' Government upon That Country; with Descriptive Accounts and Maps of Palembang and the Island of Banca. London: Black, Kingsbury, Parbury, and Allen.

Crawfurd, John. 1820a. History of the Indian Archipelago: Containing an Account of the Manners, Arts, Languages, Religions, Institutions, and Commerce of Its Inhabitants, Vol. I. Edinburgh \& London: Archibald Constable and Co. \& Hurst, Robinson, and Co. Cheapside.

Crawfurd, John. 1820b. History of the Indian Archipelago: Containing an Account of the Manners, Arts, Languages, Religions, Institutions, and Commerce of Its Inhabitants, Vol. II. Edinburgh \& London: Archibald Constable and Co. \& Hurst, Robinson, and Co. Cheapside. 
Crawfurd, John. 1820c. History of the Indian Archipelago: Containing an Account of the Manners, Arts, Languages, Religions, Institutions, and Commerce of Its Inhabitants, Vol. III. Edinburgh \& London: Archibald Constable and Co. \& Hurst, Robinson, and Co. Cheapside.

De Clercq, F.S.A. 1877. "De Hoofdplaats Palembang" dalam Tijdschrift van het Aardrijkskundig Genootschap, Vol. 2, hlm. 174-175.

De Kock, A.H.W. 1846. "Schetsen van Palembang" dalam Tijdschrift voor Nederlandsch Indië, Vol. 8, No. 3, hlm. 281-376.

De la Faille, P. de Roo. 1929. "Uit den Palembangschen Sultanstijd", dalam Feestbundel Uitgegeven door het Koninklijk Bataviaasch Genootschap van Kunsten en Wetenschappen bij Gelegenheid van Zijn 150 Jarig Bestaan, 1778-1828, Vol. 2, hlm. 316-352.

De Sturler, W.L. 1843. Proeve Eener Beschrijving van het Gebied van Palembang. Groningen: J. Oomkens.

De Sturler, W.L. 1855. Bijdrage tot de Kennis en Rigtige Beoordeling van den Zedelijken, Maatschappelijken en Staatkundigen Toestand van het Palembangsche Gebied. Groningen: J. Oomkens.

Gibson, Walter Murray. 1855. The Prison of Weltevreden; and a Glance at the East Indian Archipelago. New York: J.C. Riker.

Gramberg, J.S.G. 1878. Palembang: Historisch-romantische Schets uit de Geschiedenis van Sumatra. Batavia-Haarlem: H.M. van Dorp.

Hanafiah, Djohan. 1989. Kuto Besak: Upaya Kesultanan Palembang Menegakkan Kemerdekaan. Jakarta: Haji Masagung.

Hanafiah, Djohan. 1995. Melayu Jawa: Citra Budaya dan Sejarah Palembang. Jakarta: RajaGrafindo Persada.

Locher-Scholten, Elsbeth. 2008. Kesultanan Sumatra dan Negara Kolonial: Hubungan Jambi-Batavia (1830-1907) dan Bangkitnya Imperialisme Belanda. Jakarta: KITLV-Banana.

Marsden, William. 1811. The History of Sumatra, Containing an Account of the Government, Laws, Customs, and Manners of the Native Inhabitants, with a Description of the Natural Productions, and a Relation of the Ancient Political State of That Island. London: J. M'Creery, Black-Horse-Court. 
Muljana, Slamet. 1981. Kuntala, Sriwijaya dan Suwarnabhumi. Jakarta: Yayasan Idayu.

Muljana, Slamet. 2011. Sriwijaya. Yogyakarta: LKiS.

Nas, Peter J.M. 2007. Kota-Kota Indonesia: Bunga Rampai. Yogyakarta: Gadjah Mada University Press.

Peeters, Jeroen. 1997. Kaum Tuo-Kaum Mudo: Perubahan Religius di Palembang 1821-1942. Jakarta: INIS.

Praetorius, C.F.E. 1843. Eenige Bijzonderheden omtrent Palembang. Leyden: H.W. Hazenberg en Comp.

Santun, Dedi Irwanto M. Santun, Murni, dan Supriyanto. 2010. Iliran dan Uluan: Dinamika dan Dikotomi Sejarah Kultural Palembang. Yogyakarta: Eja Publisher.

Santun, Dedi Irwanto Muhammad. 2011. Venesia dari Timur: Memaknai Produksi dan Reproduksi Simbolik Kota Palembang dari Kolonial sampai Pascakolonial. Yogyakarta: Ombak.

Supriyanto. 2013. Pelayaran dan Perdagangan di Pelabuhan Palembang 1824-1864. Yogyakarta: Ombak.

Taal, Sandra. 2003. Between Ideal and Reality: Images of Palembang. PhD thesis. Leiden University.

Tanjung, Ida Liana. 2019. Palembang dan Plaju: Modernitas dan Dekolonisasi di Perkotaan Sumatera Selatan Abad ke-20. Yogyakarta: Ombak.

Van Alkemade, J.A. van Rijn. 1883. "De Hoofdplaats Palembang" dalam Tijdschrift van het Aardrijkskundig Genootschap, Vol. 7, hlm. 51-69.

Van Sevenhoven, J.I. 1823. "Beschrijving van de Hoofdplaats van Palembang" dalamVerhandelingen van het Bataviaasch Genootschap van Kunsten en Wetenschappen, Vol. 9, hlm. 39-126.

Veth, P.J. 1867. Schets van het Eiland Sumatra. Amsterdam: P.N. van Kemp.

Wallace, Alfred Russel. 1869. The Malay Archipelago: The Land of the Orang-utan, and the Bird of Paradise. A Narrative of Travel, with Studies of Man and Nature. London: Macmillan and Company. 
Wargadalem, Farida R. 2017. Kesultanan Palembang dalam Pusaran Konflik (18041825). Jakarta: Kepustakaan Populer Gramedia-Ecole française d'ExtrêmeOrient.

Woelders, M.O. 1975. Het Sultanaat Palembang 1811-1825. 's-Gravenhage: Martinus Nijhoff.

Zed, Mestika. 2003. Kepialangan, Politik, dan Revolusi: Palembang 1900-1950. Jakarta: LP3ES. 